\title{
Cineclubismos: uma
} história do Cineclube Antônio das Mortes Cineclub movements: a history of Antônio das Mortes Cineclub

Marina da Costa Campos $^{1}$

\footnotetext{
${ }^{1}$ Doutoranda em Meios e Processos Audiovisuais pela Escola de Comunicações e Artes da Universidade de São Paulo. Mestre em Imagem e Som pela Universidade Federal de São Carlos e graduação em Comunicação Social - bacharelado em Jornalismo, pela Universidade Federal de Goiás. Pesquisa financiada Coordenação de Aperfeiçoamento de Pessoal de Nível Superior (Capes). E-mail: marina.dacosta@gmail.com
} 
Resumo: este artigo trata da história do Cineclube Antônio das Mortes, entidade que existiu na cidade de Goiânia entre os anos de 1977 e 1987 e que desenvolveu atividades de exibição e debate, grupos de estudos e produção audiovisual. Pretende-se estudar sua atuação e a constituição de diferentes perfis ao longo de sua trajetória, com o objetivo de compreender como a entidade configurou-se num espaço múltiplo de formação audiovisual local e de como abrigou compreensões diferentes sobre a atividade cineclubista.

Palavras-chave: Cineclube Antônio das Mortes; cineclube; experimental; crítica.

\begin{abstract}
Antônio das Mortes Cineclub, an entity that existed in the city of Goiânia (GO), Brazil, between 1977 and 1987 and which developed exhibition and debate activities, study groups and audiovisual production. The objective is to study its performance and the constitution of different profiles throughout its trajectory, with the intention of understanding how the entity was configured in a multiple space of local audiovisual formation and of how to shelter different understandings about the cine-club activity.
\end{abstract}

Keywords: Antônio das Mortes Cineclub; cineclub; experimental; criticism. 


\section{Introdução}

No ano de 1984, o jovem Ricardo Musse recebeu uma ligação de seu amigo, Lourival Belém², informando-lhe que estava portando uma câmera de vídeo. Os dois decidem comunicar os amigos do cineclube ao qual pertenciam e imediatamente reúnem-se para fazer uma gravação que resultaria no média-metragem João Bennio, Glauber Rocha e o cinema goiano (1984)³, de Ricardo Musse. Localizados na Rua 96 do Setor Sul de Goiânia e também no centro da cidade, mais especificamente no Teatro Goiânia, realizam improvisadamente um diálogo entre Glauber Rocha (interpretado por Musse) e João Bennio (interpretado por Leonardo do Carmo) em que falam sobre cinema. Imitando o cineasta baiano nas reportagens produzidas para o programa Abertura, da TV Tupi em 1979, os jovens também entrevistam pessoas nas ruas, questionando suas opiniões sobre o cenário cultural da capital goiana, o gosto pelo cinema brasileiro, a repercussão da morte de Glauber Rocha e o domínio da televisão.

Esse vídeo, uma mistura de ficção com documentário, experimental, é definido pelo próprio Ricardo Musse, em texto escrito no jornal goiano O Popular de 12 de janeiro de 1986, por "seu caráter de farsa, de paródia, de sátira”, numa vídeo-performance "antropofágica” que visa a desmistificação da imagem do cineasta genial e a compreensão da formação do imaginário coletivo goiano” (MUSSE, 1986, p. 27). No entanto, mais que uma produção de crítica do seu tempo, o média-metragem apresenta também uma outra perspectiva: a possibilidade de identificar ali o Cineclube Antônio das Mortes (CCAM ou CAM). Partindo desse ponto, pode-se pensá-lo como uma metáfora da própria entidade: cita o cineasta que mais influenciou seus integrantes; traz a ironia e a provocação na abordagem do próprio cinema e da cultura local - reflexo que também marca os debates e a postura de seus membros - e a busca pela experimentação cinematográfica. Portanto, assistir a tal filme, assim como outros produzidos pelos integrantes que fizeram parte da entidade, é ter um pouco de contato com o que representou e resultou a experiência do CCAM.

Essa entidade surgiu entre os anos 1977 e 1978 e durante dez anos realizou atividades de exibição, debates, grupos de estudos, produção audiovisual e produção crítica, sendo, nesse período, uma das protagonistas de difusão e agitação cultural na capital de Goiás, além de possuir papel importante na descentralização do ensino e da cultura audiovisual no estado. Portanto, este artigo dedica-se a mostrar tal

\footnotetext{
${ }^{2}$ Atualmente, Lourival Belém é médico psiquiatra e Ricardo Musse é docente do curso de Ciências Sociais da Universidade de São Paulo.

${ }^{3}$ Este filme pode ser encontrado em cópia DVD no Museu da Imagem e Som de Goiânia.
} 
percurso e a refletir sobre seus diferentes perfis e sobre de que maneira a entidade configurou-se num espaço múltiplo de formação audiovisual local. Antes, porém, faz-se necessário localizar esse objeto dentro dos estudos já desenvolvidos sobre cineclubismo no Brasil.

\section{O cineclubismo como objeto de pesquisa}

Desde o final dos anos 1990, uma parcela de pesquisadores de cinema no Brasil vem se dedicando ao estudo específico dos cineclubes brasileiros. E nessas pesquisas sempre é possível ter acesso às origens do cineclubismo no país: o pioneirismo com Adhemar Gonzaga, Álvaro Rocha, Paulo Vanderley, Luis Aranha, Hercolino Cascardo e Pedro Lima, com o Cineclube Paredão nos anos 1917; o Chaplin Club, oficialmente o primeiro cineclube do Brasil, criado por Otávio de Faria, Plínio Sussekind Rocha, Almir Castro e Cláudio Mello em 1928; nos anos 1940, o Clube de Cinema de São Paulo fundado na Faculdade de Filosofia, Letras e Ciências Humanas da Universidade de São Paulo por Paulo Emílio Salles Gomes, Décio de Almeida Prado, Lourival Gomes Machado e Cícero Cristiano de Souza (GATTI, 1997, p. 128). Nesse aspecto de construção da trajetória do cineclubismo brasileiro é preciso destacar o livro de Ismail Xavier, Sétima arte, um culto moderno: o idealismo estético e o cinema (1978), que dedica um trecho à abordagem do Chaplin Club; e as pesquisas autônomas ${ }^{4}$ de Felipe Macedo, cineclubista e ex-presidente do Conselho Nacional de Cineclubes e de Diogo Gomes, também cineclubista, que escreveram diversos artigos para periódicos, como a revista CineclubeBrasil. Outros dois pesquisadores acadêmicos desse tema são: André Gatti que escreveu o verbete "cineclube" na Enciclopédia do Cinema Brasileiro, não só conceituando o termo, mas tratando da história do movimento no Brasil até o início dos anos 1990, tratando também do assunto em seu livro A exibição cinematográfica: ontem, hoje e amanhã (2008); e Débora Butruce, cineclubista, cujo artigo "Cineclubismo no Brasil: esboço de uma história" (2003) traz um panorama histórico do tema desde as origens até os anos 2000.

Saindo desse espectro histórico, as pesquisas referenciadas no começo deste subtópico aprofundam-se nas histórias dos cineclubes locais. Disto podem-se citar alguns trabalhos: O cinema em Belo Horizonte: do cineclubismo à produção cinematográfica na década de 1960 (1997), de José Américo Ribeiro, que

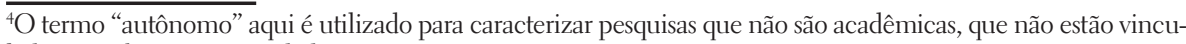
ladas a nenhuma universidade. 
se dedica ao estudo histórico do Centro de Estudos Cinematográficos do Cineclube Belo Horizonte e do Cineclube Universitário, ambas entidades fortemente ativas nos anos 1960; Quando éramos jovens: história do Clube de Cinema de Porto Alegre (2000), de Fatimarlei Lunardelli, que trata de um dos mais antigos cineclubes ainda ativos no país, focando nos primeiros 50 anos de existência da entidade; Católicos e cinema na capital paulista - o Cine Clube do Centro Dom Vital e a Escola Superior de Cinema São Luis (1958-1972), de Vivian Malusá (2007), que aborda não só a entidade a qual pertenceram Jean-Claude Bernardet, Rudá de Andrade e Gustavo Dahl como também estuda as relações entre a Igreja Católica e o cineclubismo no Brasil; O Cineclube Universitário de Campinas (1965-1973), de Natasha Hernandez, que trata tanto das atividades de exibição desse cineclube na década de 1960 como também dos textos escritos para jornais, além dos três curtas-metragens produzidos pela entidade: Um pedreiro (1966), O artista (1967) e Dez jingles para Oswald de Andrade (1972); Cineclubismo: memórias dos anos de chumbo, de Rose Clair, que aprofunda-se nas experiências cineclubistas do Rio de Janeiro durante a época da ditadura. A autora recolhe vários depoimentos de ex-cineclubistas para compreender não só a existência dessas entidades num período de grande repressão como também a prática cineclubista enquanto atividade de formação audiovisual.

Esses são alguns estudos, entre outros, poucos, que vêm sendo desenvolvidos e que apresentam como ponto em comum a perspectiva do cineclubismo como uma ação de formação. A leitura atenta desses trabalhos possibilita identificar diversas práticas realizadas dentro de um cineclube que extrapolam a ideia de um espaço alternativo de exibição de filmes e de debates - o que por si só já se institui como uma atividade educativa. Alguns cineclubes desenvolveram a prática da crítica cinematográfica ou dedicaram-se à produção cinematográfica - ou às duas atividades juntas. As escolhas dos filmes exibidos refletem um contexto histórico e também a orientação que o cineclube almeja. Por exemplo: a Igreja Católica compreende o cinema, entre 1920 e 1960, como uma experiência educativa na qual é possível tratar aspectos morais a serem seguidos ou não, de acordo com sua ortodoxia, e a partir dos anos 1960 ela, junto dos movimentos sociais, vai apresentar outras formas de participação, algumas de mais engajamento político (MALUSÁ, 2007). É preciso ressaltar também que grande parte dos cineastas tanto brasileiros como de outros países é oriunda dessa experiência cineclubista, como Glauber Rocha, Joaquim Pedro de Andrade, Leon Hirszman, Jean-Claude Bernardet, entre outros, além de diretores, críticos etc. 
Nesse aspecto, o cineclube atua, então, como um local em que o público tem contato com uma cultura audiovisual, estimulando outras formas de materialização dessa experiência, seja na escrita, na realização de filmes, em pesquisas ou até mesmo na formação de um novo olhar para com a sociedade e sua organização. Rose Clair utiliza o termo "experiências instituintes" para caracterizar, principalmente nos anos 1970, mas que pode ser estendido para um contexto mais amplo - o cineclubismo dentro de uma perspectiva de espaço coletivo para discussão estética e política:

denomino de experiências "instituintes" aquelas que se constituem em movimentos que surgem em diferentes tempos e espaços engendrados por sujeitos históricos, envolvidos em ações coletivas, capazes de trazer mudanças significativas/ éticas no processo político, social e cultural que estão vivendo. (CLAIR, 2008, p. 20)

Entendendo essa relação de várias atividades e de suas extensões em uma vida cultural, política e cultural, este artigo propõe-se a analisar o caso do CCAM como uma experiência que atende a essa ideia de formação audiovisual e que, em conjunto com as outras pesquisas sobre o tema, reforça a compreensão de que estudar a história do cineclubismo é se deparar com múltiplas tendências de cineclubismos ao longo de sua trajetória. Nesse ínterim, a história do próprio CCAM foi dividida em fases, identificando os diversos perfis e as maneiras de interação com a entidade e da entidade.

\section{Uma história do CCAM: a primeira fase (1977-1979)}

Embora não seja possível estabelecer com precisão a data de fundação do CCAM, os depoimentos colhidos com os integrantes da entidade indicam que as reuniões iniciais se deram no ano de 1977. Naquele momento, um grupo de estudantes de medicina da Universidade Federal de Goiás (UFG), liderados por Leonardo de Camargo e Antônio Carlos de Gusmão ${ }^{5}$, reunia-se nas noites de sábado no Diretório Central dos Estudantes (DCE) da UFG para exibir filmes e discutir questões políticas, com o intuito de agregar mais jovens para o movimento estudantil. Os encontros eram clandestinos e não havia documentos que confirmassem a existência dessas reuniões, pelo receio de repressões do regime militar. Tais alunos eram ajudados pelo professor do curso de comunicação social da UFG, Hélio Furtado do Amaral - cuja experiência com o cineclubismo era anterior, pois havia sido membro do Cineclube Dom Vital, citado anteriormente neste artigo. A esse grupo uniram-se mais dois integrantes: Lourival Belém, também estudante de medicina, e Ricardo

${ }^{5}$ Leonardo de Camargo, atualmente, é cirurgião gástrico. Antônio Carlos de Gusmão é médico pediatra. 
Musse, estudante de física. Os dois seriam os responsáveis por criar o elo entre o movimento estudantil e os cinéfilos do Cine Rio, local que também frequentavam.

O Cine Rio, situado próximo à região central de Goiânia, abrigava o projeto "Cinema de Arte" aos finais de semana, com exibição de filmes que não eram veiculados no circuito comercial. Os estudantes de jornalismo Antônio e Judas Tadeu Porto ${ }^{6}$, em conjunto com o Prof. Hélio Furtado do Amaral, levaram o projeto adiante até 1978, quando foi extinto. Esses três responsáveis e grande parte do público frequentador do cinema foram estimulados por Ricardo Musse a frequentar as reuniões do DCE da UFG para dar continuidade à proposta de exibição de filmes de arte e debate após as exibições. A formação do CCAM se deu dessa confluência de dois grupos, adquirindo seus contornos com a própria escolha do nome da entidade e na participação mais ativa de alguns de seus frequentadores.

O nome da entidade foi escolhido como homenagem a Glauber Rocha e pela identificação do grupo com o seu cinema. Segundo Judas Tadeu (2013), os integrantes se identificavam com o personagem Antônio das Mortes, no sentido de almejarem o posto de "exterminadores culturais" . Esse extermínio era feito por meio da provocação, apontada por Judas como uma das características do cineclube. Tal característica provocativa permeou o desenvolvimento da entidade, mas foi de grande ênfase nessa primeira fase, focada no debate político e estético das obras, orientado pelas leituras feitas em grupos de estudos e, especialmente, pela leitura do livro $O$ discurso cinematográfico: opacidade e transparência (1977), que naquele momento tinha acabado de ser lançado.

Tal livro era considerado pelo grupo como um guia dos debates, discutindo as diversas concepções assumidas por autores e escolas quanto ao estatuto imagem/ som do cinema diante da realidade (XAVIER, 1977). Essa recuperação realizada pelo autor dos principais movimentos estéticos da história do cinema servia como uma base teórica para que o grupo não só compreendesse a linguagem cinematográfica como também identificasse os aspectos ideológicos contidos em cada filme. Ricardo Musse (2013) lembra-se que comprou o livro por acaso e após a sua leitura percebeu que "aquilo era tudo o que nós precisávamos saber sobre estética". De acordo com Lourival Belém (2013), os integrantes do cineclube eram conhecidos na cidade por estarem "sempre carregando este livro embaixo dos braços". No curta-metragem

\footnotetext{
${ }^{6}$ Antônio Ribeiro é jornalista e assessor da Câmara dos Deputados de Goiânia. Judas Tadeu é jornalista e servidor público.

${ }^{7}$ As citações dos integrantes utilizadas neste artigo são oriundas de vários depoimentos realizados durante a pesquisa de mestrado desenvolvida pela autora sobre o Cineclube Antônio das Mortes entre os anos de 2012 e 2014 pelo Programa de Pós-Graduação em Imagem e Som da Universidade Federal de São Carlos (CAMPOS, 2014).
} 
Recordações de um presídio de meninos (2009), de Lourival Belém, composto por diversos registros desse período da entidade, é possível ver o grupo sentado em bancos no centro da cidade de Goiânia realizando a leitura do livro de Ismail Xavier.

Musse afirma que a realização das atividades de estudos propiciou a formação autodidata do grupo:

Quando nós começamos a ler o livro do Ismail, puxamos mais para a estética, porque começamos a ter mais base para este tipo de discussão. Nós não tínhamos base. Nós lemos não só o livro do Ismail, mas começamos a ler outros livros sobre cinema, sobre estética, crítica literária. Fizemos praticamente um curso de formação de crítica autodidata. A gente lia livros, trocava livros. Eram coisas importantes: Walter Benjamin, Adorno, que ainda não tinham entrado no Brasil. (MUSSE, 2013, comunicação oral)

Outra influência importante exercida pelo livro, assim como as demais leituras realizadas pelo grupo, foi na escolha dos filmes exibidos pela entidade. Lourival Belém (2013) afirma que a intenção do cineclube era de exibir o maior número de filmes e as mais diversas estéticas cinematográficas possíveis. A preferência das programações dos encontros no início era, segundo Antônio Carlos de Gusmão, pela exibição de filmes nacionais, voltados para as discussões políticas do momento. Com a realização do grupo de estudos e com a saída de integrantes mais ligados ao movimento estudantil, o grupo distancia-se de uma prerrogativa mais militante e opta por uma programação mais variada, mas almejando o político de outra forma. Nas palavras de Lourival Belém (2013), “partindo do estético para o político”. Essa escolha dos filmes, é necessário destacar, estava atrelada também à sua disponibilidade. Bancando os custos das exibições, o grupo optava pelos filmes distribuídos pela Dinafilme e pela Embrafilme, que eram mais baratos, pelas embaixadas estrangeiras e pelo Instituto Goethe, que eram gratuitos.

A definição por uma ampla variedade de filmes e o distanciamento da militância estudantil ajudaram a consolidar um perfil no cineclube mais voltado para a análise fílmica e para o debate teórico, mas que não deixava de abrigar diferentes interesses e posturas ideológicas. Por exemplo, havia integrantes mais de esquerda, ou mais radicais como Zildemar Pires ${ }^{8}$ e Herondes César ${ }^{9}$, outros mais interessados em estética cinematográfica, como Oto Araújo Vale ${ }^{10}$ e Lisandro

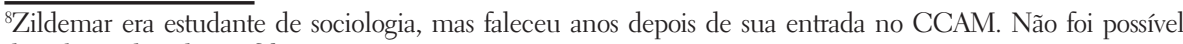
descobrir a data de seu falecimento.

${ }^{9}$ Herondes era um dos mais velhos do grupo e já trabalhava como agente bancário. Hoje encontra-se aposentado.

${ }^{10}$ Oto era estudante de letras e atualmente é professor do curso de letras da Universidade Federal de São Carlos. 
Nogueira, e Ricardo Musse, Bené de Castro ${ }^{11}$ e Lourival Belém, considerados mais polêmicos e provocadores.

A ênfase no debate e na possibilidade de ter contato com o maior número possível de obras, aliada com os estudos sobre cinema, estética e outras disciplinas, caracteriza essa primeira fase, o que demonstra uma tentativa de formação autodidata desses integrantes. O foco é a discussão ideológica, a análise fílmica como instrumento para a discussão, para circulação de ideias e, em grande parte, o motivo dos encontros desses jovens. A partir dos anos 1980, a entidade permanece com o esforço de dar prosseguimento às exibições e discussões e aos grupos de estudos, mas também mergulha numa nova proposta, que é a produção de filmes.

\section{Produção e descentralização: a segunda fase (1980 a 1984)}

A partir de 1980 o cineclube passa por uma renovação do grupo participantes. Alguns integrantes, como os já citados Ricardo Musse e Leonardo de Camargo, saem da entidade e outros novos passam a fazer parte da nova formação: Maria Noemi Araújo $^{12}$, Guaralice Paulista ${ }^{13}$, Divino Conceição ${ }^{14}$, Eudaldo Guimarães ${ }^{15}$, Luiz $\mathrm{Cam}^{16}$, entre outros. Nesse momento, por conflitos ideológicos com os movimentos estudantis que também ocupavam o espaço do DCE da UFG, o cineclube alterou o local das atividades de exibição e passou a fazer projeções em vários departamentos da universidade, como a Faculdade de Educação, a Faculdade de Direito e o Instituto de Ciências Humanas e Letras da UFG. A entidade também estabeleceu parcerias e realizou exibições na Aliança Francesa de Goiânia, no prédio da Caixa Econômica e até em bares da cidade.

O CCAM também passou a ser convidado por comunidades e por outras entidades a realizar exibições em cidades do interior de Goiás e do Mato Grosso. Segundo Beto Leão e Eduardo Benfica (1995, p. 49), o CCAM começou a estender suas atividades para os municípios do interior de Goiás visando a "criação de circuitos paralelos (cineclubes) em diversas cidades, além de estimular a realização de filmes

\footnotetext{
${ }^{11}$ Bené de Castro era jornalista na época do cineclube. Hoje é aposentado.

${ }^{12}$ Maria Noemi Araújo era estudante de pedagogia na época. Atualmente é psicanalista.

${ }^{13}$ Guaralice era estudante secundarista. Hoje é artista plástica.

${ }^{14}$ Divino Conceição era adolescente e ator quando entrou no cineclube. Hoje é cineasta e ator.

${ }^{15}$ Eudaldo era um jovem cineasta. Atualmente trabalha na produção do Festival Internacional de Cinema e Vídeo Ambiental (Fica), na cidade de Goiás, além de auxiliar em outros festivais do estado.

${ }^{16}$ Luiz Cam era estudante de arquitetura e ao longo dos anos desenvolveu a carreira de documentarista. Faleceu em 9 de junho de 2015.
} 
por parte das próprias comunidades locais". Uma das atividades realizadas foi a visita à cidade de Itapuranga ${ }^{17}$, em 1981, em um trabalho conjunto com o grupo de teatro popular Ana Félix - de maioria campesina. Luiz Cam (2013), que esteve presente nesse momento, recordou-se de que a ação visava ajudar a comunidade a pensar cinema e também colaborar e estimular um movimento incipiente de organização dos trabalhadores do campo, e não apenas a exibição de filmes. Lourival (2013) afirmou que o intuito dessas visitas, tanto nessa cidade como em outras, era de projetar filmes, discutir e ensinar os elementos estéticos e da linguagem cinematográfica. Além de Itapuranga, a entidade passou por Rio Verde ${ }^{18}$, Heitoraí19 ${ }^{19}$ Barra do Garças e Alto do Araguaia ${ }^{20}$.

A visita à cidade de Itapuranga resultou em dois filmes feitos super- 8 em conjunto com a comunidade Ana Félix: A imagem do trabalhador (1981) e $1^{\circ}$ de maio (1981). De acordo com Noemi Araújo (2013), a entidade foi chamada por um médico da cidade, Vitor, profissional que já realizava reuniões com sindicalistas, pessoas do campo e grupos de esquerda ligados à Igreja Católica. Ele apresentou ao CCAM o roteiro de A imagem do trabalhador, que tratava da migração do homem do campo para a cidade. Tanto o roteiro como a música foram elaborados coletivamente pelos camponeses. Já o outro curta-metragem trata de um registro de 15 minutos de uma passeata dos trabalhadores em um dia de visita do líder sindical Luiz Inácio Lula da Silva à cidade.

A realização de filmes é uma das atividades que a entidade passa a realizar a partir desse momento, 1981, quando surge o Núcleo de Produções do CCAM. No entanto, o núcleo não era composto por todos os integrantes, visto que a relação dos participantes era variada, de acordo com os interesses de cada um. Assim, faziam parte do núcleo: Lourival Belém, Guaralice Paulista, Divino Conceição, Eudaldo Guimarães, Luiz Cam, Noemi Araújo, Ricardo Musse, Beto Leão, Hélio de Brito, Nilson (projecionista), Ronaldo Araújo, Pedro Augusto e Márcio Belém. Lisandro Nogueira fez participações em alguns filmes.

\footnotetext{
${ }^{17}$ Itapuranga está localizada a 155 km de distância de Goiânia e pertence ao Vale São Patrício, no centro do estado de Goiás.

${ }^{18}$ Rio Verde está localizada na região sudoeste do estado de Goiás, a 220 km de distância de Goiânia.

${ }^{19}$ Heitoraí está localizada na região central do Estado de Goiás, a 132 km de distância de Goiânia.

${ }^{20}$ Barra do Garças está localizada na região nordeste do Mato Grosso, a 550 km de distância de Cuiabá. Alto do Araguaia situa-se na região sudeste do estado, a $418 \mathrm{~km}$ de capital.
} 


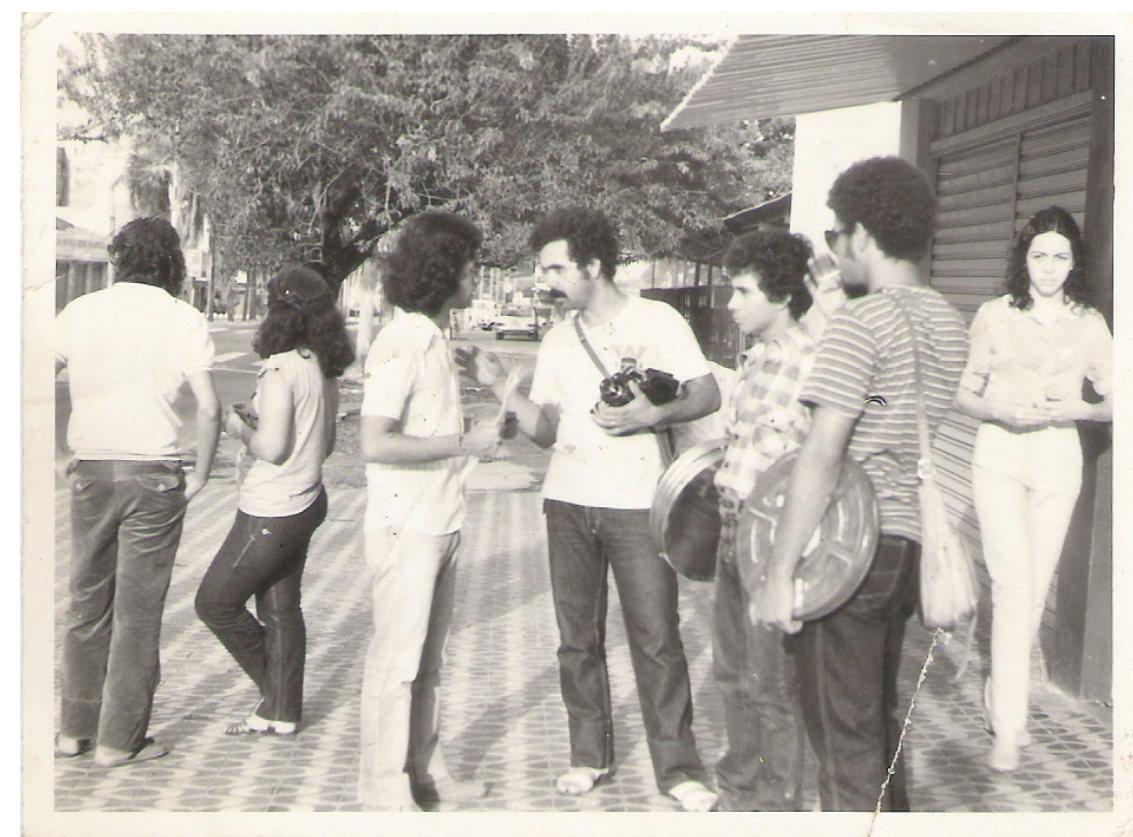

Figura 1: Foto tirada em 1981 nas filmagens do filme A ilusão, uma verdade 24 vezes por segundo, que anos depois se chamaria Recordações de um presídio de meninos. Da esquerda para direita: Ricardo Musse, Noemi Araújo, Lourival Belém, Ronaldo Araújo, Erivaldo Nery (Piolho) e Divino Conceição. Fonte: Noemi Araújo.

O núcleo funcionava em forma de cooperativa, na qual cada participante desempenhava uma função na produção, revezando-se de acordo com as necessidades de cada filme. Produziram trabalhos em super- 8 e 16 mm, e os gastos com as películas, com a compra de uma câmera de super- 8 e com o aluguel da câmera de 16 mm também eram divididos coletivamente. Noemi Araújo (2014) recorda-se que a maior influência que o grupo sofreu para a compra do equipamento veio da ideia de Glauber Rocha e do grupo cinemanovista da "câmera na mão e uma ideia na cabeça". Mas o impulso maior de produção deu-se a partir de uma doação realizada pela emissora TV Anhanguera (filiada à Rede Globo), de 220 latas de filme virgem de 16 mm. Com isso, o cineclube pôde produzir mais filmes e teve mais liberdade para experimentar. No entanto, Lisandro Nogueira (2013) lembra que essa doação, na verdade, era composta por filmes estragados, inutilizados pela emissora por conta da transição para o videotape. Já Hélio de Brito (2013) afirmou que “eram tantas latas que a gente oferecia para quem quisesse filmar". Para Eudaldo (2013), essa possibilidade de produção conduziu o cineclube a um outro patamar de reconhecimento, sendo seus integrantes denominados pelas emissoras locais de “a nova geração de cineastas dos anos 1980". 
No total foram produzidos 15 filmes, sendo 11 curtas-metragens e quatro médias-metragens, excluindo as produções não finalizadas: Nosso cinema, seus aspectos e sua gente (1981, Eudaldo Guimarães, super-8); 295.5 (1981, Lourival Belém, 16 mm); SIMA: Sistema de Informação do Mercado Agrícola (1981, Lourival Belém; Noemi Araújo, super-8); O homem que veio de Patis (1981, Hélio de Brito); A imagem do trabalhador (1981, CAM e Comunidade Ana Félix, super-8); $1^{\circ}$ de maio (1981, CAM e Comunidade Ana Félix, super-8); Quinta Essência (1982, Lourival Belém e Ronaldo Araújo, 16 mm); A ilusão - uma verdade 24 vezes por segundo (1982, Lourival Belém, 16 mm); O grande circo Vera Cruz (1983, Hélio de Brito, super-8); Conceição my Love (1984, Hélio de Brito, 16 mm); Sonhos e fantasias (1981, Eudaldo Guimarães, 16 mm); Ventos de Lizarda (1982, Pedro Augusto, 16 $\mathrm{mm}$ ); Cinzas da quarta-feira - ou a procura do eu perdido (1984, Hélio de Brito, 16 mm); Lúcidos ou neuróticos? (1982, Divino Conceição, 16 mm); Dedo de Deus (1987, Lourival Belém; Márcio Belém, super-8); e João Bennio, Glauber Rocha e o povo goiano (1986, Ricardo Musse, vídeo) ${ }^{21}$.

Uma característica comum desses trabalhos é a escolha do experimental como possibilidade de processo criativo e tentativa de extrapolar uma linguagem comercial convencional - intenção que já constava no estatuto de fundação da entidade, elaborado no ano de 1978:

Art. $2^{\circ}-$ Tem por objetivos principais:

a) Apresentar filmes de qualquer qualidade no campo da arte e da técnica cinematográfica;

b) Realizar conferências, cursos, mesas-redondas e seminários, editar boletins, promover concursos e manter uma biblioteca e arquivo para estudos e debates de assuntos de cinema em geral. c) Incentivar a prática e o progresso do filme experimental. (GOIÂNIA, 1978, p. 15)

Esse projeto inicial da entidade pode ser associado com uma afirmação, feita em um artigo publicado pelo CCAM no jornal Diário da manhã no ano de 1982, de que o cineclube já tinha uma carga teórica grande e que partia naquele momento para a produção. Pode-se intuir que havia chegado o momento de partir para a produção:

\footnotetext{
${ }^{21}$ Dos 15 filmes realizados pelo cineclube, sete podem ser acessados. À exceção de João Bennio, Glauber Rocha e o povo goiano, que está em cópia DVD no Museu de Imagem e Som de Goiás, as outras obras podem ser encontradas na internet. Os filmes de Hélio de Brito e Pedro Augusto podem ser visualizados no site YouTube. Os curtas de Lourival Belém podem ser encontrados no site da F64 Filmes. Os curtas-metragens de Euldado Guimarães e Divino Conceição encontram-se com os próprios cineastas em suas bitolas originais. Os demais filmes citados desapareceram ou não estão mais em condições de serem projetados.
} 
Depois de tantos filmes vistos, estudados, discutidos; tantos livros devorados, debatidos, tantas tardes de sábados de estudos, chegou-se às primeiras experimentações, começando-se pelo S-8, fazendo-se documentários, ficções, curtas, médias e até longas-metragens. Quem quis, fez. Apesar de muitas dificuldades, da falta de apoio e de material humano, a "trancos e barrancos", alguma coisa saiu. Fazia-se "vaquinhas", um filme aqui, outro ali; conseguia-se 500 pés de Super $8 \mathrm{~mm}$ e fazia-se um curta. E assim por diante. De curta em curta o cineasta enche a tela. (CINECLUBE ANTONIO DAS MORTES, 1982, p. 28)

As atividades promovidas antes da formação do núcleo (exibições, debates, grupos de estudos) permitiram aos integrantes o contato com diversas estéticas cinematográficas, o que os estimulavam a experimentar outras linguagens além da narrativa clássica. Para Lourival Belém, o experimental era essa possibilidade de liberdade do processo criativo:

ele [o cinema experimental] exige uma abertura, uma necessidade, uma condição de favorecimento do gênio criativo, que isso é uma dimensão - no meu entendimento - que tende a ser podada pelas condições mercadológicas, do próprio capitalismo, da massificação, da racionalização extremada, da planificação de tudo. No experimental você tem uma possibilidade de se desamarrar disso. [...] E você se põe naquele lugar onde o confortável, o cômodo não cabe mais. (BELÉM, 2013, comunicação oral)

Mesmo com uma busca pela perspectiva experimental, é preciso destacar que a ideia de "cinema experimental" não era única e nem era uma espécie de "manifesto" para essa prática do grupo. Para Guaralice Paulista (2013), antes de participar do cineclube desconhecia o que era cinema experimental. Já Ronaldo Araújo (2013b), compreendia este experimentalismo com “a própria vontade do grupo em fazer cinema. Tudo o que a gente fazia era experimental, porque a gente não sabia fazer". Logo, pode-se intuir que havia experimentalismos diversos, a partir do entendimento individual de cada integrante sobre esse campo. Além disso, tais produções eram marcadas pela variedade de gêneros e temas, como é possível verificar na mesma publicação citada acima:

Do classicismo "hollywoodiano" ao vanguardismo, tem de tudo. Como todo cineasta que começa, as influências são variadas. Divino Josée 22 diz ser influenciado por René Clair; Eudaldo Guimarães tem influências marcantes de Roman Polanski; Hélio de Brito de Alain Resnais; Zezeu Rosa é chamado de

\footnotetext{
${ }^{22}$ Nesta citação tem-se a referência à Divino José, que na verdade é Divino da Conceição. Neste artigo utilizamos o nome de Divino Conceição, pois é o nome artístico utilizado pelo cineasta atualmente.
} 
"felliniano"; Lourival Belém se diz identificado com a lentidão e o psicologismo do alemão Wim Wenders; Lisandro Nogueira, de Pasolini. Tudo isso a nível internacional. Na verdade, só uma coisa é patente: a grande influência, que de certa forma inspira todos, é a do brasileiro Glauber Rocha. Glauber talvez seja para todos nós o mesmo que o russo Eisenstein foi para os cineastas dos chamados "cinemas novos", os cinemas de reação aos moldes clássicos de Hollywood. (CINECLUBE ANTONIO DAS MORTES, 1982, p. 28)

Cada integrante se inspirava e exprimia em seus filmes a marca das influências dos autores citados, que eram exibidos e discutidos nas sessões do CCAM. Costurando todas estas produções está Glauber Rocha, com sua proposta de uma nova linguagem cinematográfica e a frase "uma câmera na mão e uma ideia na cabeça”.

Assim, a partir dessa segunda fase, é possível identificar a ideia de movimento: tanto no sentido do grupo se deslocar por vários locais para realizar suas projeções e ensino da prática audiovisual quanto no sentido da dedicação a uma nova atividade, que era a produção de filmes. Mantém-se, nos primeiros anos da década de 1980, o engajamento na apreciação da linguagem cinematográfica para se chegar aos temas políticos. Permanece também o espírito libertário dentro dos debates e na própria estrutura do cineclube. Porém, algumas transformações podem ser citadas. Quando o cineclube passa a fazer sessões em outros locais, abre-se o circuito para um público não somente estudantil, mas de profissionais, professores, comunidades. No núcleo central encontram-se não só intelectuais, mas também autodidatas, como é o caso de Eudaldo Guimarães e Divino Conceição. Consolida-se aí um movimento de lançarse para outras direções, não só das novas atividades, mas de levar o debate para outros locais. O cineclube continua com a ênfase no diálogo e na troca de ideias, só que o debate se torna ampliado, saindo do entorno universitário e se materializando em outros espaços, carentes da prática da discussão, e em outras formas de existência, como a ação de filmar.

\section{Estabilidade especializada: a terceira fase (1985 a 1987)}

Entre 1985 e 1987, parte dos integrantes deixou a entidade, restando poucos no comando: Márcio Belém, Luiz Cam, Lourival Belém, Eudaldo Guimarães e Lisandro Nogueira - este último assumindo a responsabilidade maior. O núcleo de produção se desfaz, mas alguns integrantes continuam na produção de filmes de forma independente. Os grupos de estudos são extintos, mas tem-se a realização esporádica de cursos, e o foco consolida-se na exibição com debate posterior. 
As sessões passam a ser realizadas em uma sede fixa, no Conselho Regional de Engenharia e Arquitetura de Goiás (CREA-GO), agora com a diferença de sempre contar com a presença de convidados para debaterem as temáticas dos filmes, dando um novo perfil ao projeto da entidade de formação de público. Outras duas características importantes desse momento são aumento de público (maior parte profissionais liberais) devido à divulgação constante nos periódicos da cidade e à regularidade da programação (todas às sextas e aos sábados) - programação esta composta de filmes brasileiros pertencentes à Embrafilme e do Cinema Novo Alemão pertencente ao Instituto Goethe. A experiência no CREA-GO foi considerada por Lisandro (2013) como "uma revolução, pois ali aprimoramos a ideia de formar público de cinema para Goiânia."

Essa mudança de perfil gerou reverberações positivas e negativas entre os membros e ex-membros do cineclube. Luiz Cam afirma que a periodicidade das sessões resultou na maior popularidade adquirida pelo CCAM:

A cidade sabia. Podia chover canivete que as pessoas sabiam que sexta e sábado tinha sessão. Ali também você tinha uma projeção boa numa sala confortável com ar condicionado. Condições adequadas de projeção. Quando se tem isso, mostra que há compromisso com o público e ele acaba confiando na programação. (CAM, 2013, comunicação oral)

Já Noemi Araújo discorda da ideia da periodicidade, destacando a mudança de objetivos da entidade:

O compromisso era com números, quantas pessoas, se deu mídia. Se deu visibilidade para o CREA. O cineclube era utilizado como meio para dar visibilidade para a diretoria daquela gestão do conselho. Ali já não era o cineclube. Éra o CREA que estava utilizando o CCAM como ponte. (ARAÚJO, 2014, comunicação oral)

A presença de especialistas convidados para abordar temas específicos tratados nos filmes também foi um ponto de diferenciação entre as fases do cineclube, segundo Ricardo Musse:

Quando era no DCE, não tinha um expositor, diferente do que era no CREA. No DCE era um debate: terminava a sessão, algumas pessoas ficavam, não eram muitas. Ao contrário disso, no modelo do CREA, as pessoas ficavam. Acho que a figura de um especialista, um debatedor, atraía as pessoas. No DCE, os grupos eram menores: dez, quinze pessoas. A gente fazia uma roda e conversava sobre o filme. Questões temerosas e políticas entravam na discussão, então muita gente ficava amedrontada. (MUSSE, 2013, comunicação oral) 
Esta nova modalidade das exibições do cineclube, com a presença de um expositor, e a retomada de cursos, prática da primeira e segunda fase, fazem parte do projeto dos integrantes que trabalhavam na organização da entidade na época, mais especificamente Lisandro Nogueira, de formação de público para cinema. No entanto, esta presença de um especialista traz a questão: ela não modificaria a própria estrutura do cineclubismo, pautado pelo debate horizontal entre o público?

Em 23 de julho de 1985, na data da estreia das programações do CCAM no CREA-GO, foi publicado no jornal O Popular um manifesto escrito por ex-integrantes questionando a entidade enquanto um "cineclube", sua existência, sua proposta e sua atividade cultural. De acordo com o manifesto, criticava-se a escolha dos convidados para a primeira sessão do cineclube, indicados por um "grupo fechado e escolhido". A carta também caracterizava a cerimônia como "narcisista" devido a uma prevista distribuição de medalhas que ocorreria durante a cerimônia aos "dirigentes [grifo do autor] do cineclube que agem movidos por uma ideologia do tipo 'o cineclube c'est moi" (PORTO, 1985, p. 15). Na mesma carta tem-se uma caracterização do que era o cineclube em épocas anteriores:

\begin{abstract}
Vale salientar que, à época da fundação do cineclube, organizado de forma coletiva e democrática, seus diretores, voltados primordialmente para as necessidades culturais da população, permitiram o livre debate, a inscrição de sócios e o acesso de toda a população às atividades programadas. Inclusive inscrevendo tais princípios nos estatutos, intensos à atitude elitista dos que buscam a satisfação pura e simples de interesses privados e o uso da cultura como instrumento de poder pessoal. (PORTO, 1985, p. 15)
\end{abstract}

Diante desses conflitos e questionamentos sobre os rumos do CCAM, levantam-se alguns aspectos que ajudam a compreender a constituição dessa terceira fase. O primeiro é a inserção de especialistas nos debates, pois se por um lado a presença de um convidado auxiliava no projeto da entidade de formar o público - porque se trazia uma pessoa que entendia do assunto e que podia transmitir esse conhecimento -, por outro alterava a estrutura do cineclube, que sempre reforçou a inexistência de uma hierarquia, portanto, de uma autoridade. Outro ponto é a questão do local da exibição, um espaço institucional, diferente do anterior, a universidade. Essa alteração era entendida como uma mudança dos princípios iniciais, visto que a autonomia do grupo poderia ser reduzida. Também existiu um maior conflito geracional entre seus integrantes, visto que as críticas se davam em razão dos caminhos tomados pela entidade ao longo dos anos. Tem-se um grupo, ligado à organização do cineclube na primeira e na segunda fases, que questiona a 
terceira fase e a postura "narcisista" de uma diretoria que não dava continuidade aos princípios iniciais de criação do cineclube: o livre debate e participação da população.

É preciso destacar que nessa terceira fase não se tem aquele circuito criado no setor universitário, no qual os jovens circulavam, e sim há um foco maior na exibição. Os integrantes dos primórdios do cineclube, se já não eram adultos na época, a essa altura já haviam se tornado, e com isso havia maiores responsabilidades e mudanças de destino. A entidade não contava mais com a dedicação exclusiva de seus integrantes. O contexto político era diferente, o reverbera também nos próprios objetivos de lutas e discussões - o movimento cineclubista era outro.

Nesse período, parte dos cineclubes transformou-se em salas de projeção por questões de sobrevivência das sessões. Segundo Rubens Machado Júnior (2014) - que foi cineclubista e participou do movimento entre os anos de 1970 e 1980 -, o cineclubismo deixou de lado o caráter de "movimento estudantil radical" e passou a se profissionalizar. Essa alteração, nas palavras de Rubens, constituiu num "paradoxo, visto que os cineclubes continuaram engajados, mas apenas no espírito e não no sentido prático". Esta transformação e paradoxo também podem ser observados no CCAM. Depois de 1985, os temas para debate eram outros, o público era bem diferente daquele inicial, composto por estudantes. A roda de debate foi substituída por uma mesa com convidados postados à frente dos espectadores, o que trouxe outra dinâmica para as discussões. A formação era a preocupação básica. Tais mudanças foram consequências das transformações da década, do grupo que estava à frente da entidade e da própria maneira de pensar o cineclubismo.

A partir de 1988, o cineclube passou a realizar sessões esporádicas até 1999. Entre 1989 e 1990 foram promovidas algumas sessões no Cine Cultura, espaço recém-criado naquele momento pela prefeitura de Goiânia. A entidade tornou-se inativa quanto à realização de sessões e debates, permanecendo ativa, entretanto, em muitas ações individuais de seus integrantes, pois estes sempre carregam o nome do cineclube como "realizadores" de atividades como as produções audiovisuais de Lourival Belém, Eudaldo Guimarães e a mostra "O Amor, a Morte e as Paixões", promovida por Lisandro Nogueira de 2000 a 2005 e de 2011 até março de 2017.

\section{Cineclubismos}

As fases descritas partem da análise e da observação dos contornos e das tendências que o CCAM adquiriu ao longo de seus dez anos de atividade intensa. As diferenças e semelhanças que as fases apresentam refletem as adaptações pelas 
quais o cineclube passou, de acordo com as transformações do momento políticosocial da época e refletem as alternativas que a entidade buscou para manter suas atividades de exibição. Portanto, as associações com instituições e a condução dessas parcerias demonstram a necessidade e a flexibilidade que o grupo teve que ter para permanecer ativo, explicitando, principalmente, os diferentes perfis que a entidade teve e o pensamento das pessoas que a comandavam - diferenças que mostram que o cineclube tem a marca não só de uma pessoa, mas de várias que se propuseram a divulgar a cultura cinematográfica.

As diferentes atividades desenvolvidas pelo cineclube mostram um potencial do grupo de repensar o conceito de cineclubismo e de imprimir identidades diversas que não esvaecem seu sentido, e sim o enriquecem. Elas também demonstram o objetivo de formação que a atividade cineclubista apresenta. Quem participou do CCAM, seja como integrante ligado à organização das atividades, seja como espectador ou até mesmo desinteressado nas sessões mas interessado no encontro com outras pessoas, teve a oportunidade de estar em contato com diversas estéticas cinematográficas, com intensas discussões sobre vários temas políticos, estéticos, filosófico etc., e com a prática audiovisual. Trata-se de movimentos de formação que proporcionaram à capital de Goiás uma possibilidade de desenvolver uma ampla cultura audiovisual.

Num aspecto mais amplo, o movimento cineclubista brasileiro também caminha nessa trajetória: por ser um movimento permeado por variados contextos e sujeitos, não pode ser tomado como uma estrutura fixa e homogênea, e sim cambiante e com complexas perspectivas e ideologias que conduzem seus rumos. Esse olhar, que identifica singularidades, diversidades e transformações, deve estar presente em uma pesquisa sobre este tema, independente se ela se localiza em algo mais específico, como entidades locais, ou possui viés panorâmico. O estudo dos movimentos de ação que extrapolam a sala de cinema convencional e vão além também da produção cinematográfica traz perspectivas enriquecedoras e estimulantes para os estudos históricos do cinema. 


\section{Referências}

ARAÚJO, M. N. [Sem título]. 2013. Entrevista concedida a Marina Costa, São Paulo, 28 fev. 2013a.

$2013 b$

[Sem título]. 2013. Entrevista concedida a Marina Costa, Goiânia, 21 jul. 2014.

[Sem título]. 2014. Entrevista concedida a Marina Costa, São Paulo, 7 jan.

BUTRUCE, D. Cineclubismo no Brasil: esboço de uma história. Acervo, Rio de Janeiro, v. 16, n. 1, p. 117-124, jan./jun., 2003.

CAMPOS, M. C. Cineclube Antônio das Mortes: exibição, produção e crítica (19771987). Dissertação (Mestrado em Imagem e Som) - Universidade Federal de São Carlos, São Carlos, 2014.

BELÉM, L. Recordações de um presídio de meninos. [Filme-vídeo]. Direção de Lourival Belém. Goiânia, 2009. 2013. [Sem título]. 2013. Entrevista concedida a Marina Costa, Goiânia, 15 jan.

BRITO, H. O. de. [Sem título]. 2013. Entrevista concedida a Marina Costa, 10 jul. 2013. Via correio eletrônico.

CINECLUBE ANTÔNIO DAS MORTES. Cineclube mais uma vez pede passagem. Diário da Manhã, Goiânia, 14 set. 1982. Em cartaz, hoje no cinema, p. 28. (Acervo do Instituto Histórico e Geográfico de Goiás).

CAM, L. [Sem título]. 2013. Entrevista concedida a Marina Costa, Goiânia, 22 jun. 2013.

CLAIR, R. Cineclubismo: memórias dos anos de chumbo. Rio de Janeiro: Luminária Academia, 2008.

GATTI, A. "Cineclube”. In: RAMOS, F.; MIRANDA, L. F. (Org.). Enciclopédia do cinema brasileiro. São Paulo: Senac, 1997. P. 128-130.

A exibição cinematográfica: ontem, hoje e amanhã. São Paulo: Centro Cultural São Paulo, 2008.

GOIÂNIA (Cidade). Estatuto interno do Cineclube Antônio das Mortes. Livro da ata de registro de reuniões e assembleias. Diário Oficial do Município de Goiânia, Goiânia, 5 mai. 1978, p. 15. (Acervo de Lourival Belém).

LEÃO, B.; BENFICA, E. Goiás no século do cinema. Goiânia: Kelps, 1995.

LUNARDELLI, F. Quando éramos jovens: história do Clube de Cinema de Porto Alegre. Porto Alegre: UFRGS: Secretaria Municipal de Cultura, 2000.

MACHADO JÚNIOR, R. [Sem título]. 2014. Entrevista concedida a Marina Costa, Goiânia, 8 jan. 2014.

MALUSÁ, V. Católicos e cinema em São Paulo: o Cineclube do Centro Dom Vital e a Escola Superior de Cinema São Luís. Dissertação (Mestrado em Multimeios) Universidade Estadual de Campinas, Campinas, 2007. 
MUSSE, R. João Bennio, Glauber Rocha e o cinema goiano. [Filme-vídeo]. Direção de Ricardo Musse. Goiânia, 1986. (Acervo pessoal de Ricardo Musse). 2013. [Sem título]. 2013. Entrevista concedida a Marina Costa, Goiânia, 4 mar.

NOGUEIRA, L. [Sem título]. 2013. Entrevista concedida a Marina Costa, Goiânia, 25 jul. 2013.

PAULISTA, G. [Sem título]. 2013. Entrevista concedida a Marina Costa, Goiânia, 21 fev. 2013.

PORTO, J. T. “Glauber Rocha, João Bennio e o povo goiano”. O Popular, Goiânia, 12 jan. 1986, p. 27. (Acervo do Instituto Histórico e Geográfico de Goiás). 2013. [Sem título]. 2013. Entrevista concedida a Marina Costa, Goiânia, 24 jun.

RIBEIRO, J. A. O cinema em Belo Horizonte: do cineclubismo à produção cinematográfica na década de 1960. Belo Horizonte: UFMG, 1997.

XAVIER, I. O discurso cinematográfico: opacidade e transparência. Rio de Janeiro: Paz e Terra, 1977.

Sétima arte: um culto moderno: o idealismo estético e o cinema. São Paulo: Perspectiva, 1978. 